\title{
A Randomized Controlled Pilot Study Assessing Feasibility and Impact of Yoga Practice on Quality of Life, Mood, and Perceived Stress in Women With Newly Diagnosed Breast Cancer
}

Author Affiliations Sandhya Pruthi, MD, and Daniela L. Stan, MD, are consultants, Division of General Internal

Medicine; Sarah M.

Jenkins is a statistician and Marianne Huebner,

$\mathrm{PhD}$, is a research consultant, Division of Biomedical Statistics and Informatics; Beth A. Borg, $\mathrm{RN}, \mathrm{MHA}$, is an adminis-

trator and Barbara S. Thomley is a complementary and integrative medicine coordinator, Division of General Internal Medicine; Susanne M. Cutshall, MS, $\mathrm{RN}, \mathrm{CNS}$, is an integrative health specialist, Department of Surgery; Ravinder Singh, $\mathrm{PhD}$, is a consultant, Department of Laboratory Medicine and Pathology; Sadhna Kohli, PhD, is an associate consultant, Oncology Research; Judy C. Boughey, MD, is a consultant, Division of General Surgery, and Valerie Lemaine, MD, MPH, is a senior associate consultant, Division of Plastic Surgery, Department of

Surgery, all at Mayo Clinic, Rochester, Minnesota. Lise Solberg Nes, $\mathrm{PhD}$, is a psychologist in the Department of

Medicine, University of Minnesota, Minneapolis.

Correspondence Sandhya Pruthi, MD pruthi.sandhya@ mayo.edu

Citation Glob Adv Health Med. 2012;1(5):28-33.

Key Words Breast cancer, yoga, quality of life, pilot study, fatigue, stress

Disclosure The authors declare no competing interests.

一项评估瑜伽练习对新诊断出患有乳腺癌的女性的生活质量、情绪和感知到的压力之 可行性和影响的随机对照试验研究

Estudio piloto controlado y aleatorizado para evaluar la viabilidad y el impacto de la práctica de yoga sobre la calidad de vida, el estado de ánimo y el estrés percibido en mujeres con cáncer de mama de reciente diagnóstico

Sandhya Pruthi, MD, United States; Daniela L. Stan, MD, United States; Sarah M. Jenkins, United States; Marianne Huebner, PhD, United States; Beth A. Borg, RN, MHA, United States; Barbara S. Thomley, United States; Susanne M. Cutshall, MS, RN, CNS, United States; Ravinder Singh, PhD, United States; Sadhna Kohli, PhD, United States; Judy C. Boughey, MD, United States; Valerie Lemaine, MD, MPH, United States; Lise Solberg Nes, PhD, United States

\section{ABSTRACT}

Background: A breast cancer diagnosis can entail numerous physical and psychosocial challenges. Yoga practice (YP) may contribute to improved well-being for these patients.

Primary Study Objective: Investigate feasibility and impact of YP on quality of life (QoL), mood, fatigue, and perceived stress immediately after breast cancer diagnosis.

Methods: Thirty women were randomly assigned to a yoga group (YG) or control group (CG) immediately after cancer diagnosis.

Setting: Pilot study conducted at an academic medical center breast clinic. Participant(s): Females ( $=30)$ who received a biopsy-proven breast cancer diagnosis without metastatic disease. Intervention(YG): One individual YP session at baseline, then 2 individual and 8 weekly group sessions followed by weekly gentle yoga at home (DVD). Questionnaires and saliva samples (ie, cortisol) completed at baseline and I 2 weeks postdiagnosis.

Results: Both groups reported significant improvements in QoL postintervention but with no significant difference between groups. Emotional well-being, mood-related tensionanxiety, depression-dejection, and confusion-bewilderment scores improved for both groups, and cortisol and cortisone levels decreased. Lumpectomies were prevalent with
YG (67\%) and CG (47\%). YP was rated as "very effective," providing relaxation (85\%), stress relief (69\%), and reduced muscle tension/general feeling of wellness (each 62\%).

Conclusion: Feasibility of YP immediately after breast cancer diagnosis was good. Improvement in emotional well-being, anxiety, depression, and levels of confusion was found in both groups. To our knowledge, this is the first study examining the impact of YP immediately after breast cancer diagnosis. Further research in this area is warranted.

\section{背景}

背景: 乳腺癌的诊断结果可能要使 患者承受诸多身体和心理挑战。瑜 伽练习 (YP) 或有助于改善这些患 者的身心健康。

主要研究目标：研究 YP 对紧接乳 腺癌诊断后的生活质量 (QOL)、情 绪、疲劳和感知到的压力之可行性 和影响。

方法：三十名女性在癌症诊断后立 即被随机分配至一个瑜伽小组 ( $\mathrm{YG}$ ) 或对照小组 $(C G)$ 。

机构: 试验研究在一个学术医疗中 心的乳房诊所开展。

参与者: 已经活检确诊是乳腺癌而 癌症尚无转移的女性 $(\mathrm{N}=30)$ 。

干预 (YG): 基线时安排一次个人 YP 课程, 然后安排 2 次个人课程 和 8 次每周小组课程, 最后每周在 家进行柔和瑜伽锻炼（DVD）。于基
线时和诊断后 12 周展开问卷调查 并采集唾液样本（即皮质醇）。

效果: 干预后, 两组均报告 QOL 显著改善, 但两组无明显区别。两 组的情感健康、情绪相关紧张一紧 张一焦虑、抑郁一沮丧, 及混乱一 困惑分数均有所提高, 皮质醇和皮 质酮水平下降。两组中进行乳房肿 瘤切除术的比例较大, $Y G$ 组为 $67 \%$ , 对照组为 $47 \%$ 。 $\mathrm{YP}$ 被评为 “非常 有效” ，让人放松 (85\%)、缓解精 神压力 $(69 \%)$ 及缓解肌肉紧张 / 大 体感觉健康（各为 $62 \%$ )

结论: 紧接乳腺癌诊断后 YP 可行 性良好。两组的情绪健康、焦虑、 抑郁和混乱程度有所改善。据我们 所知, 这是首次紧接乳腺癌诊断后 验证 YP 之影响的研究。此领域的 进一步研究已获批准。

\section{SINOPSIS}

Fundamentación: Un diagnóstico de cáncer de mama puede conllevar numerosos retos físicos y psicosociales. La práctica de yoga puede contribuir a la mejora del bienestar de estos pacientes.

Objetivo principal del estudio: Investigar la viabilidad y el impacto de la práctica de yoga sobre la calidad de vida (CdV), el estado de ánimo, el cansancio y el estrés percibidos inmediatamente después del diagnóstico de cáncer de mama.

Métodos: Se asignó un grupo de treinta mujeres a un grupo de yoga (GY) o 
de control (GC) inmediatamente después del diagnóstico de cáncer.

Ámbito: Estudio piloto realizado en una clínica de la mama de un centro médico académico.

Participante(s): Mujeres ( $\mathrm{N}=30$ ) que recibieron un diagnóstico de cáncer de mama sin metástasis demostrado mediante biopsia.

Intervención (YG): Una sesión individual de práctica de yoga al inicio; a continuación, 2 sesiones individuales y 8 sesiones semanales en grupo, seguidas de yoga suave semanal en su hogar (DVD). Se rellenaron cuestionarios y se tomaron muestras de saliva (por ejemplo, para la determi- nación de cortisol) al inicio y I2 semanas después del diagnóstico.

Resultados: Ambos grupos notificaron mejoras significativas en la CdV posintervención, sin diferencia significativa entre los grupos. En ambos grupos mejoraron las puntuaciones de bienestar emocional, tensión-tensión-ansiedad relacionadas con el estado de ánimo, las puntuaciones de depresión-abatimiento y confusióndesconcierto, y disminuyeron las concentraciones de cortisol y cortisona. Las mastectomías parciales fueron prevalentes, con un $67 \%$ en el GY y un $47 \%$ en GC. La práctica de yoga se calificó de "muy efectiva" en la relajación ( $85 \%$ ), el alivio del estrés (69 \%) y la reducción de la tensión muscular o mejora de la sensación de bienestar general (62 \% cada una).

Conclusiones: La viabilidad de la práctica de yoga inmediatamente después del diagnóstico de cáncer fue buena. En ambos grupos se hallaron mejoras en el bienestar emocional, la ansiedad, la depresión y los niveles de confusión. Que sepamos, este es el primer estudio que explora el impacto de la práctica de yoga inmediatamente después del diagnóstico de cáncer de mama. Se aconseja continuar la investigación en este área.

\section{INTRODUCTION}

Women with a new diagnosis of breast cancer frequently experience stress, emotional distress, anxiety, and fatigue before, during, and after treatment. Quality of life (QoL) in the first year after breast cancer diagnosis is significantly affected ${ }^{\mathrm{I}}$ and correlates positively with survival. $^{2}$ Alternative methods of exercise like yoga have shown promise in improving QoL in breast cancer survivors. 3,4 Yoga is a complementary, mind-body exercise and relaxation strategy. 5 The term yoga comes from a Sanskrit word that means yoke (harmony) or union, and yoga has been described as the union of mind, body, and spirit, consisting of skills, tools, or techniques such as pranayama (breath work); asana (physical postures, movement); and meditation (concentration, mental clarity, and awareness). According to Yoga Journal, I I million people in the United States perform yoga occasionally, and approximately 6 million practice yoga on a regular basis. In small pilot studies, hatha yoga, the most commonly practiced form of yoga in the United States, has been found to decrease stress, anxiety, and fatigue. ${ }^{6-9}$

Studies designed using yoga to assess physical and psychological benefits, QoL, emotional outcomes, and fatigue in breast cancer survivors have primarily shown positive and beneficial effects. ${ }^{8}$ Studies of individuals participating in stress reduction programs such as yoga or other mindfulness-based exercises also have shown a reduction in salivary cortisol levels, ${ }^{\text {IO,II }}$ which can be a surrogate marker for stress levels. Breast cancer malignancy has been associated with activation of the hypothalamic-pituitary-adrenal (HPA) axis, and the biopsychological aspects of a new cancer diagnosis can subsequently result in cortisol dysregulation. ${ }^{\text {II }}$ Salivary cortisol and cortisone were therefore also examined in this study.

Even though the effects of yoga have been studied in breast cancer survivors at different stages of treatment, there is limited data on the effects of yoga in the immediate postdiagnosis period. The pilot study sought to examine the feasibility of a yoga practice (YP) in the period immediately following a breast cancer diagnosis. We hypothesized that compared with the control group (CG) participants, participants in a yoga group (YG) would experience improvement in QoL, mood, stress, and fatigue, and we predicted a greater decrease in cortisol levels from pre- to posttreatment in the YG.

\section{METHODS AND DESIGN}

Thirty women with a new diagnosis of biopsyproven breast cancer were enrolled between November I, 20I0, and August 30, 20I I. Participants were recruited from the Breast Cancer Clinic at Mayo Clinic in Rochester, Minnesota, where they received preoperative education and counseling regarding potential breast cancer surgical options.

\section{Participants}

Participants were female, aged 2I years or older, with a recent biopsy-proven diagnosis of noninvasive or invasive breast cancer without evidence of metastatic disease, with plans to undergo the standard treatment of surgery for breast cancer, and residing within a 45-minute driving distance of the local yoga studio where classes were conducted.

Exclusion criteria included patients previously having participated in regular yoga classes (I or more days per week), having maintained a regular personal practice of yoga in the past 3 months, or otherwise planning to start yoga while being enrolled in the study. In addition, those patients planning to receive neoadjuvant chemotherapy, being pregnant, or not speaking English were excluded. The study was approved by the Mayo Clinic Institutional Review Board.

\section{Intervention}

Participants were randomly assigned to either the YG $(n=I 5)$ or the CG ( $n=I 5)$. Information about demographics, breast cancer diagnosis, stage of disease, and prescribed treatment regimen (surgery, chemotherapy, radiation) were collected from medical charts. Both groups completed baseline surveys and provided a baseline salivary 
cortisol sample. After study completion, participants in the CG were offered 8 weekly, 6o-minute yoga sessions, similar to the YG.

\section{Measures}

Participants completed the following surveys and evaluation pre- and postintervention.

Mayo Clinic Complementary and Alternative Therapy (CAM) Survey. This survey collects information about previous participation in other complementary and alternative therapy programs, as well as satisfaction and perceived effectiveness of the intervention.

Functional Assessment of Cancer TreatmentBreast Cancer (FACT-B). The FACT-B is a 44-item instrument measuring multidimensional QoL in patients with breast cancer. ${ }^{\mathrm{I} 2}$

Perceived Stress Scale (PSS). The PSS is a widely used Io-item, self-report instrument measuring the perception of stress. ${ }^{\text {I3 }}$

The Profile of Mood States-Short Form (POMSSF). The POMS-SF is a 37-item short form of the Profile of Mood States measuring psychological distress. ${ }^{\mathrm{I} 4}$

Brief Fatigue Inventory (BFI). The BFI is a 9-item scale asking patients to rate their current, usual, and worst level of fatigue in the last 24 hours. ${ }^{\text {I5 }}$

Salivary cortisol levels. All participants provided single salivary cortisol samples at baseline and at I2 weeks for assessment of cortisol levels. Samples were collected using Salivette devices (Sarstedt Salivette Supply TI54, Nümbrecht, Germany).

\section{Yoga Practice Intervention}

The YG participants ( $\mathrm{n}=\mathrm{I}$ ) ) were instructed by a registered yoga instructor (ie, a minimum of 200 hours of yoga training and in good standing with the Yoga Alliance). Participants received three individual therapeutic yoga sessions (6o minutes). The first session was individualized at the time of consent, and participants were given information on YP assessment and the first component of yoga, pranayana (breath work). The second and third individual yoga sessions started I week after surgery at a local yoga studio. The yoga offered was a combination of gentle and hatha yoga, which included pranayama and gentle movements of the upper and lower body on a chair or mat. Those in the YG were asked to attend one weekly 6o-minute gentle YG class for 8 weeks during the postoperative period (week 4 to week I2). All participants received a gentle yoga DVD to use at home at least once per week.

\section{Control Group}

The CG ( $n=15)$ continued with usual care before and after the surgical procedure. Following the study completion, the CG participants were offered eight free yoga classes and provided with a yoga DVD.

\section{Main Outcome Measures}

Participant characteristics and outcomes were summarized with frequencies and percentages for categorical data and with mean and range (or median and interquartile range [IQR] where appropriate) for continuous data. Cortisol, cortisone, QoL, mood, fatigue, and perceived stress levels within each treatment group were compared between baseline and I 2 weeks postintervention with Wilcoxon signed-rank tests, and the pre- and post- differences were compared between treatment groups with Wilcoxon rank-sum tests. Although this was designed as a pilot study and thus underpowered to detect small differences, $P$ values $<.05$ were considered statistically significant. All analyses were performed using SAS version 9 (Cary, North Carolina).

\section{RESULTS}

For recruitment, 43 patients were approached over the course of 9 months (recruitment rate, 70\%). Feasibility of the intervention was good, and adherence to protocol high, with I5 participants (IO0\%) in the YG attending the first individual session and I3 (87\%) attending all three individual yoga sessions (Figure I). Six patients (40\%) attended five or more of the recommended eight group sessions (median 3 classes), and I I $(73 \%)$ reported performing the home-based, DVDguided exercises at least once weekly. One participant (7\%) in each group dropped out of the study (Figure 2).

The groups were similar in baseline characteristics (Table I) with the YG having a higher rate of lumpectomy vs mastectomy. Radiation was more common in the YG, but this is to be expected given the higher lumpectomy rate.

\section{Quality of Life and Mood}

Certain aspects of QoL and mood improved significantly within both groups. The emotional wellbeing (FACT-B) QoL score increased by a median 2.5 points in the YG $(P=.02)$ and by 4.5 points in the CG $(P$ $=.007$ ). Tension-anxiety, depression-dejection, and confusion-bewilderment mood scores (POMS) also significantly improved within both groups (median improvements ranged from 0.4 to o.9). There was no significant difference between the YG and CG with respect to preand postintervention, with the exception of social/ family well-being $(P=.045)$ where improvement was slightly higher for the CG (median improvement, 2.5) than the YG (median improvement, o; Table 2).

\section{Perceived Stress and Fatigue}

Perceived stress level improved similarly in the YG (median improvement, I.5; $P=.03$ ) and CG (median improvement, I.5; $P=.06$ ). Fatigue level did not significantly change from pre- to postintervention (Table 2).

\section{Cortisol and Cortisone}

Cortisol and cortisone levels decreased from pre- to postintervention. Cortisol and cortisone levels changed by a median of Io.o ng/dL $(P=.32)$ and 86.o ng/dL $(P=.32)$, respectively, within the YG and by a median of I2.I ng/dL $(P=.02)$ and $74.5 \mathrm{ng} / \mathrm{dL}(P=.09)$, respectively, within the CG. There was no difference in the level of decrease between groups $(P=.55$ and $P=.92$, respectively; Table 2$)$. 

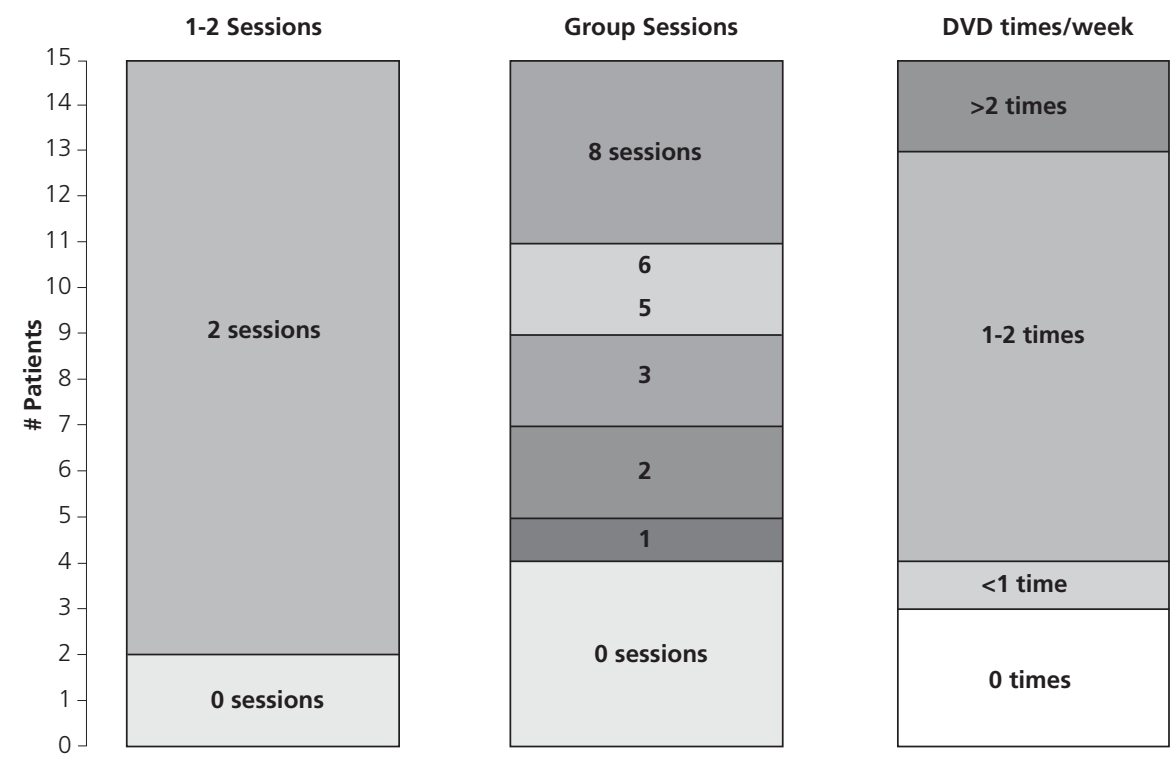

Figure 1 Yoga adherence.

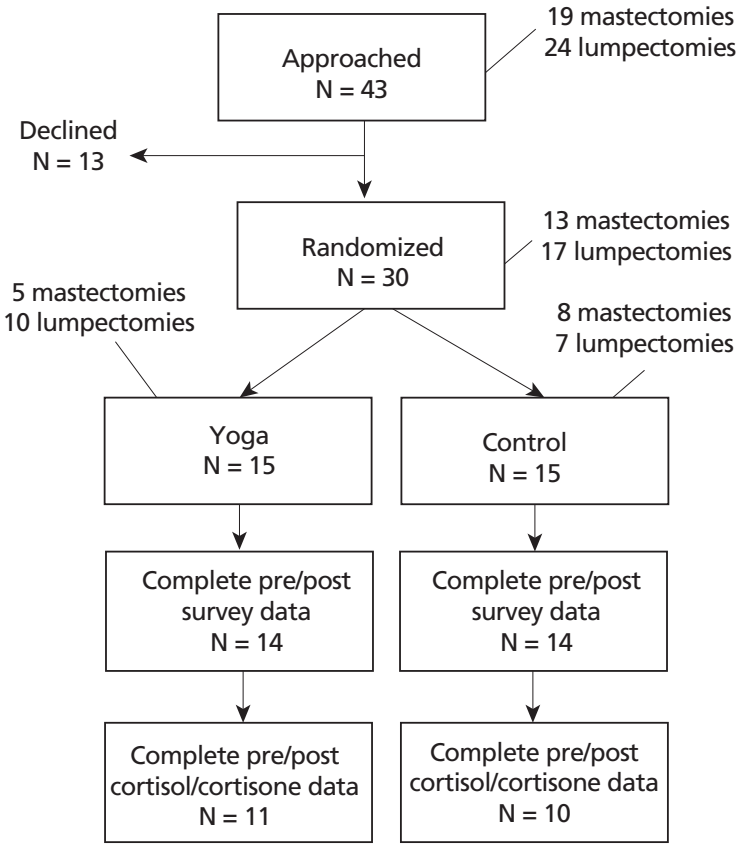

Figure 2 Flow of patients through the study.

\section{Yoga Ratings, Sessions, and Rated Effectiveness}

There was no correlation between the total number of exercise sessions performed and outcome measures (data not shown). Feasibility and adherence was high, however, and the YP was rated as "very effective," providing relaxation ( $85 \%$ ), stress relief (69\%), and reduction of muscle tension or general feeling of wellness (each $62 \%$ ).

\section{Limitations}

Because this was a pilot study, our sample size was small, and it is possible that one might have seen different or more significant results with a larger sample. Given that the patients were recently diagnosed and all
Table 1 Baseline Characteristics and the Subsequent Treatment Modalities

\begin{tabular}{lcc} 
& Control $(\mathbf{n}=15)$ & Yoga $(\mathbf{n}=15)$ \\
\hline $\begin{array}{l}\text { Age (y), mean (range) } \\
\text { Type of surgery, } \mathrm{n}(\%)\end{array}$ & $55(40-73)$ & $58(48-75)$ \\
\hline $\begin{array}{l}\text { Mastectomy } \\
\text { Lumpectomy }\end{array}$ & $8(53)$ & $5(33)$ \\
\hline $\begin{array}{l}\text { Adjuvant therapy, } \mathrm{n}(\%) \\
\text { None }\end{array}$ & $7(47)$ & $10(67)$ \\
$\begin{array}{l}\text { Hormonal therapy only } \\
\text { (Arimidex, Tamoxifen) }\end{array}$ & $5(33)$ & $1(7)$ \\
\hline $\begin{array}{l}\text { Radiation ( } \pm \text { hormonal therapy) } \\
\text { Chemotherapy ( } \pm \text { radiation or } \\
\text { hormonal therapy) }\end{array}$ & $4(27)$ & $3(20)$ \\
\hline
\end{tabular}

were undergoing treatment, the nonactive CG could potentially also have benefited from more rest. Asymptomatic patients possibly being enrolled could also have contributed to the somewhat unclear trends seen in these primary investigations. With regard to salivary cortisol, additional measures collected at specific times during the day and more than twice during the study could potentially provide clearer evidence of cortisol changes throughout the study. The YG had more patients with lumpectomy than the CG, which had more patients who underwent mastectomy. This may have minimized the potential benefit from yoga as patients with mastectomy had prolonged recovery and may have more potential benefit from YP.

\section{DISCUSSION}

This study sought to examine the feasibility of YP started at the time of breast cancer diagnosis and potential impact on QoL, mood, stress, fatigue, and cortisol levels. 


\begin{tabular}{|c|c|c|c|c|c|}
\hline & \multicolumn{2}{|l|}{ Yoga } & \multicolumn{2}{|l|}{ Control } & \multirow{2}{*}{$\begin{array}{c}\text { Yoga vs Control } \\
P^{b}\end{array}$} \\
\hline & $\begin{array}{c}\text { Post-Pre } \\
\text { median (IQR) }\end{array}$ & $p^{a}$ & $\begin{array}{c}\text { Post-Pre } \\
\text { median (IQR) }\end{array}$ & $p^{a}$ & \\
\hline \multicolumn{6}{|l|}{ QoL (FACT-B) ${ }^{c}$} \\
\hline Physical well-being & $-1.5(-7.0,0.0)$ & $.03^{d}$ & $-0.8(-9.0,1.0)$ & .14 & .69 \\
\hline Social/family well-being & $0.0(-2.0,1.0)$ & .40 & $2.5(0.0,3.7)$ & $.03^{d}$ & $.045^{d}$ \\
\hline Emotional well-being & $2.5(0.0,5.0)$ & $.02^{\mathrm{d}}$ & $4.5(1.0,6.0)$ & $.007^{d}$ & .45 \\
\hline Functional well-being & $1.0(-3.0,3.0)$ & .98 & $-0.5(-1.0,4.0)$ & .79 & .85 \\
\hline FACT-G: Total & $2.4(-11.0,7.0)$ & .92 & $3.5(-2.0,11.0)$ & .35 & .43 \\
\hline FACT-B: Additional concerns & $2.0(0.0,4.0)$ & .13 & $1.5(-1.0,5.0)$ & .08 & .91 \\
\hline FACT-B: Total & $3.9(-11.0,10.0)$ & .70 & $6.5(-2.5,12.0)$ & .12 & .49 \\
\hline FACT-B: Trial outcome index & $2.5(-8.0,6.0)$ & .80 & $-0.3(-6.0,4.0)$ & .74 & .85 \\
\hline \multicolumn{6}{|l|}{ Mood (POMS) } \\
\hline Tension-anxiety & $-0.9(-1.2,-0.3)$ & $<.001^{d}$ & $-0.6(-1.0,-0.3)$ & $.007^{d}$ & .43 \\
\hline Vigor-activity & $-0.3(-1.0,0.3)$ & .30 & $-0.1(-1.0,0.3)$ & .53 & .65 \\
\hline Fatigue-inertia & $-0.4(-1.0,0.4)$ & .39 & $-0.3(-0.6,0.0)$ & .38 & .87 \\
\hline Depression-dejection & $-0.4(-0.6,0.0)$ & $.008^{\mathrm{d}}$ & $-0.4(-1.3,0.0)$ & $.03^{d}$ & .98 \\
\hline Confusion-bewilderment & $-0.8(-1.6,-0.2)$ & $<.001^{d}$ & $-0.8(-1.2,-0.4)$ & $.001^{d}$ & .84 \\
\hline Anger-hostility & $-0.2(-0.6,0.0)$ & $.04^{d}$ & $0.1(-0.7,0.4)$ & .58 & .46 \\
\hline Overall & $-0.5(-0.7,-0.1)$ & $.002^{\mathrm{d}}$ & $-0.4(-0.8,0.0)$ & $.048^{\mathrm{d}}$ & .73 \\
\hline Fatigue $(\mathrm{BFI})^{\mathrm{e}}$ & $-0.1(-0.8,0.8)$ & .99 & $-0.3(-2.7,0.7)$ & .45 & .49 \\
\hline Perceived Stress (PSS) & $-1.5(-6.0,0.0)$ & $.03^{\mathrm{d}}$ & $-1.5(-7.0,0.0)$ & .06 & .94 \\
\hline Cortisol, ng/dL & $-10.0(-39.0,2.1)$ & .32 & $-12.1(-40.9,-4.2)$ & $.02^{\mathrm{d}}$ & .55 \\
\hline Cortisone, ng/dL & $-86.0(-191.0,63.0)$ & .32 & $-74.5(-323.0,19.0)$ & .09 & .92 \\
\hline \multicolumn{6}{|c|}{$\begin{array}{l}\text { a } P \text { value comparing paired differences (post vs pre) with the Wilcoxon signed rank test. } \\
\text { b } P \text { value comparing the post/pre differences between yoga vs control with the Wilcoxon rank sum test. } \\
\text { c Positive difference }=\text { improvement. } \\
\text { d } P \leq .05 \text {. } \\
\text { e Negative difference }=\text { improvement. } \\
\text { Abbreviations: POMS. Profile of Mood States: Post postintervention. Pre oreintervention }\end{array}$} \\
\hline
\end{tabular}

Recruitment for the study was fairly quick with patients' interest in yoga relatively high (70\%). Adherence with the study protocol was good, with a majority of participants attending all three individual yoga sessions $(87 \%)$ as well as performing the home-based exercises (73\%). Attendance at studio group-sessions was somewhat lower (40\%), supporting previous research indicating that studio attendance may be much lower than home practice frequency. ${ }^{16}$ Overall recruitment and attendance records do, however, suggest feasibility of YP immediately after diagnosis.

Contrary to prediction, overall QoL did not significantly change from pre- to postintervention for either of the groups in this study. The emotional well-being subscale significantly improved within both groups but with no significant difference between groups. Other significant findings suggest that the CG improved in social wellbeing, and the YG worsened in physical well-being.

These results contradict findings from other studies of yoga vs waitlist groups in breast cancer survivors where improved $\mathrm{QoL}^{16}$ or a protective effect for social well-being $8,17,18$ have been found in the YG. Patients not receiving chemotherapy have also demonstrated significant improvement in emotional, social, spiritual, and overall QoL, and adherence has been positively associat- ed with physical well-being and negatively associated with fatigue and distressed mood. ${ }^{8}$ One small, randomized controlled study with a yoga intervention in I8 patients with more advanced breast cancer (stages II-IV) nevertheless found no improvement in QoL. ${ }^{\mathrm{I} 9}$

Our study differs significantly from the above studies in that recruitment was started at the time of breast cancer diagnosis. This is a particularly challenging time for patients, with significant emotional turmoil and impaired QoL. ${ }^{20}$ The improved emotional well-being seen across groups could potentially be a reflection of returning to baseline following the initial turmoil of diagnosis. The decrease in the physical well-being observed in our study might be secondary to treatments received including breast irradiation, but it remains unclear why this negative change was seen only in the YG, especially given the minimal side effects reported by the participants and high satisfaction reported with the intervention.

Significant improvements were seen in overall mood and multiple mood domains (tension-anxiety, depression-dejection, confusion-bewilderment, and anger hostility) across both groups with no significant between-group difference. Again, these findings are in contrast with other studies assessing similar outcomes 
and showing significant improvements in mood following yoga intervention. ${ }^{18,2 \mathrm{I}} \mathrm{A}$ possible explanation for these contradicting findings could be the fact that our participants were recruited immediately following diagnosis when patients are still attempting to adjust to the emotional turmoil of a new cancer diagnosis. It is possible that the passage of time and reassurance that the cancer is being treated could have led to significant improvement in QoL and mood well beyond a potential positive effect from a yoga intervention in this study.

Cancer diagnoses and subsequent treatments generally involve significant stressor exposure and persistent levels of fatigue. As with QoL and mood, our findings showed significant improvements in perceived stress levels for both groups, and again, these findings are contrary to existing research showing yoga interventions to be associated with improved stress levels compared with control groups. One of the most common symptoms reported by breast cancer survivors is fatigue, and it has been estimated that as many as $33 \%$ of these patients experience persistent fatigue. ${ }^{6}$ Even though a few wellconducted randomized studies have shown yoga to be associated with decreased levels of fatigue following breast cancer treatments, ${ }^{7}$ fatigue levels did not change for either group in the current study.

Cortisol level decreased from the initial measure to postintervention in both groups, although more significantly in the CG. Previous studies show contradicting findings in this area following yoga intervention, either not finding any change in cortisol slope, ${ }^{19}$ or finding significant improvement in cortisol levels for the postintervention YG. ${ }^{\mathrm{I}}{ }^{8}$

Studies examining the impact of yoga interventions in breast cancer survivors have examined a number of psychosocial factors, mainly through random recruitment. Studies targeting patients with specific symptoms, or at a very early stage in the course of illness, are rare, however. This could potentially explain how conflicting results may occur.

Results from this pilot study did not indicate clear benefits for patients undergoing YP immediately postdiagnosis. It is possible that during this period patients may be feeling overwhelmed, and the shock of the new breast cancer diagnosis may prevent them from truly benefiting from interventions. Improvements were found in emotional well-being, anxiety, depression, and levels of confusion in both groups, however, and breast cancer patients could potentially experience improvement in QoL, mood, and levels of perceived stress following treatment completion regardless of the interventions implemented. Study results show that the feasibility of YP immediately after breast cancer diagnosis was good, and adherence to individual sessions was very high. Participants pointed to relaxation as the most effective aspect of the intervention as well, indicating that YP immediately postdiagnosis may be most beneficial if individualized and if it included relaxation (eg, breathing) components. Given the novelty of this study, as well as the sample size and pilot study factors, further research is clearly warranted.
When developing future studies, in addition to increasing the sample size, we would consider offering more flexibility for participation in yoga programs immediately postdiagnosis, potentially through homebased interventions such as DVD or interactive ehealthtype practice rather than mandatory classes. Targeting patients with higher levels of symptoms such as stress, distress, or fatigue prior to the intervention may also increase the likelihood of detecting more substantial intervention benefit.

\section{REFERENCES}

I. Lu W, Cui Y, Chen X, et al. Changes in quality of life among breast cancer patients three years post-diagnosis. Breast Cancer Res Treat. 2009; I I 4 (2):357-369.

2. Epplein M, Zheng Y, Zheng W, et al. Quality of life after breast cancer diagnosis and survival. J Clin Oncol. 20I I;29(4):406-4I2.

3. Bower JE, Woolery A, Sternlieb B, Garet D. Yoga for cancer patients and survivors. Cancer Control. 2005;I2(3):I65-I7 I.

4. Buettner C, Kroenke CH, Phillips RS, Davis RB, Eisenberg DM, Holmes MD. Correlates of use of different types of complementary and alternative medicine by breast cancer survivors in the nurses' health study. Breast Cancer Res Treat. 2006; IOO(2):219-227.

5. Ross A, Thomas S. The health benefits of yoga and exercise: a review of comparison studies. J Altern Complement Med. 20I0;I6(I):3-I2.

6. Bower JE, Ganz PA, Desmond KA, et al. Fatigue in long-term breast carcinoma survivors: a longitudinal investigation. Cancer. 2006;106(4):75 I-758.

7. Bower JE, Garet D, Sternlieb B. Yoga for persistent fatigue in breast cancer survivors: results of a pilot study. Evid Based Complement Alternat Med. 2OII;20I I:623I68.

8. Moadel AB, Shah C, Wylie-Rosett J, et al. Randomized controlled trial of yoga among a multiethnic sample of breast cancer patients: effects on quality of life. J Clin Oncol. 2007;25(28):4387-4395

9. Rao MR, Raghuram N, Nagendra HR, et al. Anxiolytic effects of a yoga program in early breast cancer patients undergoing conventional treatment: a randomized controlled trial. Complement Ther Med. 2009;I7(I):I-8.

Io. Carlson LE, Speca M, Patel KD, Goodey E. Mindfulness-based stress reduction in relation to quality of life, mood, symptoms of stress and levels of cortisol, dehydroepiandrosterone sulfate (DHEAS) and melatonin in breast and prostate cancer outpatients. Psychoneuroendocrinology. 2004;29(4):448-474.

II. Robert McComb JJ, Tacon A, Randolph P, Caldera Y. A pilot study to examine the effects of a mindfulness-based stress-reduction and relaxation program on levels of stress hormones, physical functioning, and submaximal exercise responses. J Altern Complement Med. 2004;IO(5):8I 9-827.

I2. Brady M), Cella DF, Mo F, et al. Reliability and validity of the Functional Assessment of Cancer Therapy-Breast quality-of-life instrument. J Clin Oncol. I997; I5(3):974-986.

I3. Cohen S, Kamarck T, Mermelstein R. A global measure of perceived stress. J Health Soc Behav. I983;24(4):385-396.

14. Curran SL, Andrykowski MA, Studts JL. Short-Form of the Profile of Mood States (Poms-SF): Psychometric Information. Psychol Assess. I 995;7(I):80-83.

I5. Mendoza TR, Wang XS, Cleeland CS, et al. The rapid assessment of fatigue severity in cancer patients: use of the Brief Fatigue Inventory. Cancer. I999;85(5): I I 86-I I 96.

I6. Littman AJ, Bertram LC, Ceballos R, et al. Randomized controlled pilot trial of yoga in overweight and obese breast cancer survivors: effects on quality of life and anthropometric measures. Support Care Cancer. 20I 2;20(2):267-277.

I7. Rao RM, Telles S, Nagendra HR, et al. Effects of yoga on natural killer cell counts in early breast cancer patients undergoing conventional treatment. Comment to: Recreational music-making modulates natural killer cell activity, cytokines, and mood states in corporate employees. Masatada Wachi, Masahiro Koyama, Masanori Utsuyama, Barry B. Bittman, Masanobu Kitagawa, Katsuiku Hirokawa. Med Sci Monit. 2007;I3(2): CR57-70. Med Sci Monit. 2008; I4(2):LE3-4.

I8. Vadiraja SH, Rao MR, Nagendra RH, et al. Effects of yoga on symptom management in breast cancer patients: A randomized controlled trial. Int J Yoga. 2009;2(2):73-79.

I9. Banasik J, Williams H, Haberman M, Blank SE, Bendel R. Effect of Iyengar yoga practice on fatigue and diurnal salivary cortisol concentration in breast cancer survivors. J Am Acad Nurse Pract. 20I I;23(3):I35-I42.

20. Visser MR, van Lanschot JJ, van der Velden J, Kloek JJ, Gouma DJ, Sprangers MA. Quality of life in newly diagnosed cancer patients waiting for surgery is seriously impaired. J Surg Oncol. 2006;93(7):57 I-577.

2I. Banerjee B, Vadiraj HS, Ram A, et al. Effects of an integrated yoga program in modulating psychological stress and radiation-induced genotoxic stress in breast cancer patients undergoing radiotherapy. Integr Cancer Ther. 2007;6(3):242-250.
Acknowledgments We sincerely thank Lace Up Against Breast Cancer (LUABC) and the Ralph Stump and Raedene Stump Foundation for providing the funding support for this study. We thank Ms Gladdie Hebl from Mayo Clinic Grant and Publication Support Services for her editorial assistance and Ms Hilary E. Blair in the Immunochemical Core Laboratory for assistance with the cortisol assays. We appreciate the data entry support by $\mathrm{Mr}$ David Hafferty. 